\title{
EKSTRAKSI BIJI KETUMBAR DENGAN MEMPERGUNAKAN PELARUT N-HEKSANA
}

\author{
Abdullah Kuntaarsa ${ }^{1}$, Zubaidi Achmad ${ }^{2}$, Purwo Subagyo ${ }^{3}$ \\ 1,2,3 Jurusan Teknik Kimia, Fakultas Teknik Industri, Universitas Pembangunan Nasional \\ "Veteran" Yogyakarta \\ Email: 'kunta@upnyk.ac.id, ${ }^{2} z u b a i d i a c h m a d @ u p n y k . a c . i d,{ }^{3}$ subagyo_p@yahoo.com
}

Masuk: 16 Januari 2021, Revisi masuk: 27 Februari 2021, Diterima: 2 Agustus 2021

\begin{abstract}
Coriander seeds (Coriandrum sativum $L$ ) are a spice plant that has been used by humans as medicine or as food taste. Coriander seeds contain 0.8-1.8\% essential oil. Coriander essential oil has many benefits and has a long history of being used in traditional medicine. The extraction of coriander seeds can be done by using a solvent extraction process. One of the solvents used is $\mathrm{N}$-Hexane. First coriander was washed to remove dirt on coriander skin. Then the coriander was dried and mashed. After that the extraction was carried out with temperature variations of $450^{\circ} \mathrm{C}, 500^{\circ} \mathrm{C}, 550^{\circ} \mathrm{C}, 600^{\circ} \mathrm{C}$, and $630^{\circ} \mathrm{C}$ and time variations were 90,120,150, 180, 210, and 240 minutes, and solvent volume variations were $150 \mathrm{ml}, 200 \mathrm{ml}, 250 \mathrm{ml}$, and $300 \mathrm{ml}$, with a coriander seed weight of 70 grams and a constant stirring speed of $300 \mathrm{rpm}$. After being extracted, the result was filtered and then distilled to obtain pure essential oil. From this study, it was found that the best operating conditions were achieved at a temperature of $630^{\circ} \mathrm{C}$ with an oil yield of 1,260 ml. For optimal extraction time occurs at 150 minutes with an oil yield of $1.561 \mathrm{ml}$. Then for the optimal solvent volume at $200 \mathrm{ml}$ with an oil yield of $1.561 \mathrm{ml}$.
\end{abstract}

\section{INTISARI}

Biji ketumbar (Coriandrum sativum L) merupakan tanaman bumbu-bumbuan yang sejak lama digunakan dan dimanfaatkan oleh manusia sebagai obat atau untuk meningkatkan cita rasa bahan pangan. Biji ketumbar, terkandung minyak atsiri sebanyak 0,8-1,8\%. Minyak atsiri ketumbar memiliki banyak manfaat dan memiliki sejarah panjang akan kegunaannya sebagai obat tradisional. Ekstraksi biji ketumbar dapat dilakukan dengan proses ekstraksi dengan pelarut. Salah satu pelarut yang dapat digunakan ialah N-Heksana.

Ketumbar terlebih dahulu dicuci untuk membuang kotoran yang terdapat pada permukaan kulit ketumbar. Lalu ketumbar dikeringkan kemudian dihaluskan. Lalu dilakukan ekstraksi dengan variasi suhu $45^{\circ} \mathrm{C}, 50^{\circ} \mathrm{C}, 55^{\circ} \mathrm{C}, 60^{\circ} \mathrm{C}$, dan $63^{\circ} \mathrm{C}$, kemudian variasi waktu yaitu 90,120, $150,180,210$, dan 240 menit, dan variasi volume pelarut yaitu $150 \mathrm{ml}, 200 \mathrm{ml}, 250 \mathrm{ml}$, dan $300 \mathrm{ml}$, dengan berat biji ketumbar 70 gram dan dengan kecepatan pengadukan yang tetap yaitu 300 rpm. Setelah diekstraksi, hasil kemudian disaring kemudian didistilasi untuk mendapat minyak atsiri murni.

Pada penelitian ini didapat bahwa kondisi operasi terbaik dicapai pada suhu $63^{\circ} \mathrm{C}$ dengan hasil minyak sebanyak 1,260 ml. Untuk waktu ekstraksi optimal terjadi pada waktu 150 menit dengan hasil minyak $1,561 \mathrm{ml}$. Kemudian untuk volume pelarut optimal yaitu pada $200 \mathrm{ml}$ dengan hasil minyak sebanyak $1,561 \mathrm{ml}$.

Kata Kunci : Ketumbar, Ekstraksi, N-Heksana 


\section{PENDAHULUAN Latar Belakang}

Indonesia merupakan salah satu negara yang mempunyai potensi sumber daya alam yang besar, antara lain pada rempah-rempahnya. Bahkan Indonesia adalah salah satu negara pengekspor rempah-rempah terbesar di dunia. Rempah-rempah merupakan jenis tumbuhan dengan aroma dan rasa yang kuat yang sering dimanfaatkan menjadi bumbu dapur. Selain itu rempah-rempah juga banyak digunakan untuk bahan dasar kosmetik maupun obat-obatan. Karena banyaknya manfaat, tidak heran rempah-rempah menjadi salah satu komoditas dengan nilai ekonomis yang tinggi. Bahkan, pada saat zaman penjajahan, salah satu alasan utama para penjajah melakukan eksplorasi di Indonesia adalah untuk mengambil dan memanfaatkan rempah-rempahnya.

Salah satu rempah-rempah yang memiliki banyak manfaat yaitu ketumbar (Coriandrum sativum L.). Ketumbar sendiri sudah banyak digunakan sejak dahulu karena ketersediaan dan manfaatnya yang banyak. Ketumbar disebut-sebut memiliki khasiat menjadi analgesik, antiseptik, dan anti-diabetes. Selain itu ketumbar memiliki efek stimulasi pada sistem pencernaan dengan menambah produksi enzim pada pencernaan. Ketumbar juga dinilai dapat meningkatkan fungsi hati (Rashid dkk, 2014). Bahkan di Indonesia, ketumbar sudah lazim dikonsumsi untuk menjadi obat. Umumnya, ketumbar dikonsumsi dengan merendamnya di air panas dan diminum air rendamannya.

Untuk mengambil kandungan dari ketumbar, dapat pula dilakukan dengan cara ekstraksi minyak ketumbar dengan pelarut. Salah satu pelarut yang paling umum digunakan untuk ekstraksi ialah N-Heksana.

\section{Biji Ketumbar dan Kandungannya}

Tanaman ketumbar (Coriandrum sativum Linn) diduga berasal dari sekitar
Laut Tengah dan Pegunungan Kaukasus di Timur Tengah. Di Indonesia, tanaman ketumbar belum dibudidayakan secara intensif dalam skala luas, penanaman hanya terbatas pada lahan pekarangan dengan sistem tumpangsari dan jarang secara monokultur. Tanaman ketumbar (Coriandrum sativum Linn) diduga berasal dari sekitar Laut Tengah dan Pegunungan Kaukasus di Timur Tengah.(Astawan, 2009)

Biji ketumbar (Coriandrum sativum $L$ ) juga merupakan salah satu jenis tanaman bumbu-bumbuan yang sejak lama digunakan dan dimanfaatkan oleh manusia sebagai obat atau untuk meningkatkan cita rasa bahan pangan (Purseglove et al., 1981). Biji ketumbar mengandung berbagai macam mineral. Mineral yang banyak terkandung pada biji ketumbar adalah kalsium, fosfor, magnesium, potassium, dan besi. Kalsium selain berperan sebagai mineral tulang, juga berperan menjaga tekanan darah agar tetap normal. Mineral fosfor berperan dalam pembentukan dan pertumbuhan tulang. Fosfor juga berperan dalam menjaga keseimbangan asam dan basa tubuh. Magnesium merupakan mineral yang berperan dalam metabolisme kalsium dan potasium, serta membantu kerja enzim dalam metabolisme energi. Potasium membantu keseimbangan cairan elektrolit dalam tubuh. Besi merupakan mineral yang dibutuhkan dalam pembentukan sel darah merah, hemoglobin, dan mioglobin otot. (Fauci et al., 2008; Astawan, 2009).

Pada ketumbar, terkandung minyak atsiri sebanyak 0,8-1,8\%. Minyak atsiri ketumbar dikenal memiliki banyak manfaat dan memiliki sejarah panjang akan kegunaannya sebagai obat tradisional. Hal ini disebabkan karena kandungan ketumbar yang direkomendasikan untuk keluhan dyspepsia, kehilangan nafsu makan, kejang, insomnia, bahkan kecemasan. Sedangkan minyak atsiri ketumbar disebut dapat meningkatkan kontrol glukosa darah dan dapat digunakan 
sebagai agen anti-hiperglikemik (Mandal dan Mandal, 2015).

Minyak ketumbar umumnya berwarna bening hingga kuning pucat. Namun, terdapat faktor-faktor lain yang dapat mengubah warna minyak, missal karena adanya proses penguapan, reaksi oksidasi, pengubahan pelarut, dan faktor-faktor lain.

Sifat dari minyak ketumbar antara lain:

Wujud : cair, bening ke kuning pucat Titik didih : $>100^{\circ} \mathrm{C}(760 \mathrm{mmHg})$

Densitas : $0.862-0,878 \mathrm{~g} / \mathrm{mL}$ pada 20 ${ }^{\circ} \mathrm{C}$

(Material Safety Data Sheet)

\section{Ekstraksi}

Ekstraksi adalah proses dimana satu atau lebih komponen dipisahkan secara selektif dari sebuah cairan atau padatan menggunakan pelarut yang tidak dapat larut. Proses pemisahan tersebut bergantung pada kelarutan dari tiap komponen. Dari proses ekstraksi akan menghasilkan dua fase, yaitu fase ekstrak dan fase rafinat. Setelah itu untuk regenerasi pelarut, perlu dilakukan langkah pemisahan lain, misalnya distilasi.

(ETH Zurich, 2014)

Berdasarkan fasenya, ekstraksi dibedakan menjadi dua:

1. Ekstraksi padat - cair

2. Ekstraksi cair - cair

Ekstraksi gas - cair disebut absorpsi. (Gamse, tanpa tahun)

Pada percobaan ini metode ekstraksi yang digunakan adalah metode ekstraksi padat-cair atau leaching. Leaching adalah ekstraksi padat cair dengan perantara suatu zat pelarut. Proses ini dimaksudkan untuk mengeluarkan zat terlarut dari suatu padatan atau untuk memurnikan padatan dari cairan yang membuat padatan terkontaminasi. Metode yang digunakan untuk ekstraksi akan ditentukan oleh banyaknya zat yang larut, penyebarannya dalam padatan, sifat padatan dan besarnya partikel. Jika zat terlarut menyebar merata di dalam padatan, material yang dekat permukaan akan pertama kali larut terlebih dahulu. Biasanya proses leaching berlangsung dalam tiga tahap yaitu yang pertama perubahan fase dari zat terlarut yang diambil pada saat zat pelarut masuk. Kedua terjadi proses difusi pada cairan dari dalam partikel padat menuju keluar (Kusuma, 2017)

Secara umum ada lima tahap pada proses leaching:

1. Pelarut berpindah dari larutan ke permukaan padatan.

2. Pelarut menembus atau berdifusi ke dalam padatan (difusi intra partikel).

3. Solute larut dari padatan ke solven.

4. Solute berdifusi melalui campuran ke permukaan padatan (difusi intra partikel)

5. Solute akan menyebar pada larutan.

(Almohsin, tanpa tahun)

Banyak faktor yang dapat mempengaruhi proses ekstraksi, diantaranya adalah:

1. Rasio Campuran

Jumlah ekstrak akan menurun dengan jumlah pelarut yang konstan dan proporsi material simplisia yang meningkat. Dalam artian, walaupun simplisia terus ditambah, jika pelarut yang digunakan tetap maka ekstrak yang dihasilkan juga tidak akan bertambah, karena keseimbangan konsentrasi akan cepat tercapai tetapi tidak seluruh kandungan dalam simplisia terlarut dalam pelarut yang digunakan. Semakin besar rasio antara pelarut dan bahan baku, maka akan memperbesar pula jumlah senyawa yang terlarut. Akibatnya laju ekstraksi akan semakin meningkat.

2. Laju penetapan keseimbangan

Hal ini mempengaruhi waktu selesainya atau terpenuhinya proses ekstraksi. Dimana faktor ini dipengaruhi oleh:

a. Ukuran partikel dan derajat pengembangan (swelling) simplisia

Semakin kecil ukuran partikel, semakin besar luas bidang kontak antara padatan dan solven, sehingga mempercepat penetrasi pelarut ke dalam bahan yang akan diekstrak serta 
semakin pendek jalur difusinya, yang menjadikan laju transfer massa semakin tinggi dan mempercepat waktu ekstraksi. Laju ekstraksi juga meningkat apabila ukuran partikel bahan baku semakin kecil. Dalam arti lain, rendemen ekstrak akan semakin besar bila ukuran partikel semakin kecil. Tetapi, ukuran partikel juga tidak boleh terlalu kecil karena akan menyulitkan saat proses filtrasi.

Begitu juga dengan pengembangan, dimana semakin cepat terjadinya pengembangan akan semakin cepat pula terjadi proses difusi yang mempercepat proses ekstraksi karena terjadi pelebaran kapiler. Namun, adanya pengembangan karena mukus atau lendir yang terlalu banyak akan menghalangi proses ekstraksi karena proses difusi akan terhalangi oleh adanya lendir tersebut. Pengembangan simplisia ini juga dipengaruhi oleh ukuran partikel, jika partikel lebih kecil maka simplisia akan lebih cepat mengembang.

\section{b. Suhu ekstraksi}

Kelarutan bahan yang diekstraksi dan difusivitas umumnya akan meningkat dengan meningkatnya suhu, sehingga diperoleh laju ekstraksi yang tinggi.

c. Sifat pelarut yang digunakan

Sifat pelarut yang mempengaruhi laju keseimbangan konsentrasi yaitu seperti viskositas. Dimana jika viskositas besar maka akan memperlambat proses ekstraksi karena lebih membutuhkan waktu dalam proses difusinya.

d. Intensitas pergerakkan simplisia dan pelarut

Pergerakan disini maksudnya adalah adanya proses pengadukkan dalam ekstraksi. Sama halnya jika kita melakukan pengadukan pada larutan gula, pengadukan yang semakin cepat akan mempercepat proses kelarutan. Saat dilakukan pengadukan saat proses ekstraksi, maka akan lebih cepat terjadi kesetimbangan konsentrasi karena difusi semakin cepat.

3. Temperatur
Secara umum, kenaikan temperatur akan meningkatkan jumlah zat terlarut ke dalam pelarut. Temperatur pada proses ekstraksi terbatas hingga suhu titik didih pelarut yang digunakan dan perlu diperhatikan sifat termostabilitas senyawa yang akan diekstraksi. Ekstraksi akan lebih cepat dilakukan pada suhu tinggi. Suhu tinggi meningkatkan pengeluaran (desorption) senyawa dari bagian aktif (active sites) karena perusakan sel bahan meningkat. Suhu ekstraksi meningkatkan suhu pelarut secara konvektif.

Pelarut panas mengalami penurunan tegangan permukaan (surface tension) dan viskositas (viscosity). Keadaan ini meningkatkan daya pembasahan (wetting) bahan dan penetrasi matriks (Jain et al., 2009). Akan tetapi, suhu tinggi ini juga memerlukan perhatian keselamatan (safety) yang lebih intensif dalam menggunakan pelarut mudah terbakar (Kaufmann dan Christen, 2002). Suhu tinggi yang berlebihan dapat berdampak pada degradasi senyawa target secara termal

4. Jumlah proses ekstraksi

Jumlah proses ekstraksi juga meningkatkan efisiensi ekstraksi. Misalnya, empat ekstraksi dengan 50 $\mathrm{ml}$ pelarut lebih efisien dibanding satu ekstraksi dengan $200 \mathrm{ml}$ pelarut. Biasanya, rendemen dapat maksimal dengan 3-5 proses ekstraksi bahan secara berturut-turut .

5. Waktu ekstraksi

Waktu merupakan parameter penting dalam ekstraksi. Umumnya, waktu ekstraksi berkorelasi positif terhadap jumlah senyawa target, walaupun terdapat resiko terjadinya degradasi senyawa target itu sendiri. Waktu ekstraksi tergantung pada bahan yang diekstrak. (Anonim, 2015)

\section{Pelarut}

Pelarut adalah benda cair atau gas yang melarutkan benda padat, cair atau gas, yang menghasilkan sebuah larutan. Pelarut paling umum digunakan dalam kehidupan sehari-hari adalah air. Pelarut 
lain yang juga umum digunakan adalah bahan kimia organik (mengandung karbon) yang juga disebut pelarut organik. Pelarut biasanya memiliki titik didih rendah dan lebih mudah menguap, meninggalkan substansi terlarut yang didapatkan. Untuk membedakan antara pelarut dengan zat yang dilarutkan, pelarut biasanya terdapat dalam jumlah yang lebih besar.

Sebagian besar reaksi kimia secara luas dilakukan di dalam larutan. Larutan terdiri dari pelarut (solvent) dan zat terlarut (solute). Pelarut (solvent) pada umumnya adalah zat yang berada pada larutan dalam jumlah yang besar, sedangkan zat lainnya dianggap sebagai zat terlarut (solute). Pelarut memenuhi beberapa fungsi dalam reaksi kimia, dimana pelarut melarutkan reaktan dan reagen agar keduanya bercampur, sehingga hal ini akan memudahkan penggabungan antara reaktan dan reagen yang seharusnya terjadi agar dapat merubah reaktan menjadi produk. Pelarut juga bertindak sebagai kontrol suhu, salah satunya untuk meningkatkan energi dari tubrukan partikel sehingga partikel-partikel tersebut dapat bereaksi lebih cepat, atau untuk menyerap panas yang dihasilkan selama reaksi eksotermik. (Rahayu, 2017)

Faktor yang mempengaruhi dalam berhasilnya proses ekstraksi adalah mutu dan pelarut yang dipakai. Ada dua pertimbangan utama dalam memilih pelarut yang akan digunakan, yaitu harus memiliki daya larut yang tinggi dan pelarut tersebut tidak berbahaya atau tidak beracun. (Sumaatmadja, 1981)

Pelarut yang dipilih harus disesuaikan dengan beberapa kriteria berikut :

\section{Kepolaran dan kelarutan pelarut}

Pelarut yang dipilih memiliki kepolaran yang sama dengan bahan yang akan diekstrak sehingga pelarut dapat melarutkan solute dengan baik. Dengan tingkat kelarutan yang tinggi, hanya sedikit pelarut yang diperlukan.

2. Selektivitas
Pelarut diharapkan memiliki selektivitas yang tinggi sehingga hanya akan melarutkan senyawa-senyawa tertentu yang ingin diekstrak atau sedikit mungkin melarutkan senyawa-senyawa pengotor, sehingga pemisahan dari campurannya pun dapat berlangsung lebih sempurna.

3. Murah dan mudah diperoleh.

4. Tidak korosif, tidak beracun, stabil secara termal dan tidak mudah terbakar.

5. Tidak menyebabkan terbentuknya emulsi.

6. Tidak reaktif.

Pelarut hanya berfungsi melarutkan dan diharapkan tidak mengubah susunan kimia dari bahan yang diekstrak (tidak terjadi reaksi antara pelarut dengan bahan yang diekstrak).

7. Titik didih

Titik didih pelarut cukup rendah sehingga hanya membutuhkan pemanasan yang tidak terlampau besar. Bila pemanasan yang diperlukan membutuhkan energi yang sangat besar, dapat menimbulkan kerusakan pada bahan yang diekstrak dan hal seperti itu tentu saja dihindari. Namun titik didih pelarut pun tidak boleh terlampau rendah yang dapat menyebabkan kehilangan pelarut dalam jumlah yang besar akibat pemanasan. Titik didih pelarut pun harus seragam agar tidak menimbulkan residu di bahan pangan.

8. Viskositas dan densitas

Viskositas dan densitas dari pelarut diharapkan cukup rendah agar pelarut lebih mudah mengalir dan kontak dengan padatan berlangsung lebih baik.

9. Sifatnya terhadap air

Pelarut yang digunakan sebaiknya bersifat hidrofilik terlebih bila bahan yang akan diekstrak masih mengandung sedikit air. Bila pelarut yang digunakan bersifat hidrofob, pelarut yang diharapkan dapat menembus dinding sel dan melarutkan isi sel (klorofil/bahan yang akan diekstrak) akan ditolak terlebih dahulu oleh keberadaan air. 10. Kecepatan alir pelarut 
Kecepatan alir pelarut, sedapat mungkin besar dibandingkan dengan laju alir bahan ekstraksi, agar ekstrak yang terlarut dapat segera diangkut keluar dari permukaan bahan padat.

11. Temperatur

Temperatur operasi yang tinggi akan berpengaruh positif terhadap ekstraksi karena adanya peningkatan kecepatan difusi, peningkatan kelarutan dari larutan, dan penurunan viskositas pelarut. Dengan viskositas pelarut yang rendah, kelarutan yang dapat dicapai lebih besar. Temperatur yang digunakan harus dapat disesuaikan dengan kelarutan pelarut, stabilitas pelarut, tekanan uap pelarut, dan selektivitas pelarut.

(Sakinah, 2016)

Pelarut dikelompokkan menjadi pelarut non-polar, polar aprotik, dan polar protik dan diurutkan berdasarkan kenaikan polaritas. Polaritasnya dinyatakan sebagai konstanta dielektrik. Macam-macam pelarut yang biasa dipakai antara lain:

Tabel 1. Macam-Macam Pelarut

\begin{tabular}{|c|c|c|c|c|}
\hline Solvent & $\begin{array}{c}\text { Rumus } \\
\text { kimia }\end{array}$ & $\begin{array}{c}\text { Titi } \\
\mathrm{k} \\
\text { did } \\
\text { ih }\end{array}$ & $\begin{array}{c}\text { Konsta } \\
\text { nta } \\
\text { dielektr } \\
\text { ik }\end{array}$ & $\begin{array}{c}\text { Mas } \\
\text { sa } \\
\text { jenis } \\
(\mathrm{gr} / \\
\mathrm{ml})\end{array}$ \\
\hline \multicolumn{5}{|c|}{ Pelarut non Polar } \\
\hline Heksana & $\mathrm{C}_{7} \mathrm{H}_{14}$ & $\begin{array}{l}69 \\
{ }^{\circ} \mathrm{C}\end{array}$ & 2.0 & $\begin{array}{c}0.65 \\
5\end{array}$ \\
\hline Benzena & $\mathrm{C}_{6} \mathrm{H}_{6}$ & $\begin{array}{l}80 \\
{ }^{\circ} \mathrm{C}\end{array}$ & 2.3 & $\begin{array}{l}0.87 \\
9\end{array}$ \\
\hline Toluena & $\mathrm{C}_{7} \mathrm{H}_{8}$ & $\begin{array}{l}111 \\
{ }^{\circ} \mathrm{C}\end{array}$ & 2.4 & $\begin{array}{l}0.86 \\
7 \\
\mathrm{~g} / \mathrm{ml}\end{array}$ \\
\hline Dietil eter & $\left(\mathrm{C}_{2} \mathrm{H}_{5}\right)_{2} \mathrm{O}$ & $\begin{array}{l}35 \\
{ }^{\circ} \mathrm{C}\end{array}$ & 4.3 & $\begin{array}{l}0.71 \\
3 \\
\mathrm{~g} / \mathrm{ml}\end{array}$ \\
\hline
\end{tabular}

\begin{tabular}{|c|c|c|c|c|}
\hline Kloroform & $\mathrm{CHCl}_{3}$ & $\begin{array}{l}61 \\
{ }^{\circ} \mathrm{C}\end{array}$ & 4.8 & $\begin{array}{l}1.49 \\
8 \\
\mathrm{~g} / \mathrm{ml}\end{array}$ \\
\hline Etil asetat & $\mathrm{C}_{4} \mathrm{H}_{8} \mathrm{O}_{2}$ & $\begin{array}{l}77 \\
{ }^{\circ} \mathrm{C}\end{array}$ & 6.0 & $\begin{array}{l}0.89 \\
4 \\
\mathrm{~g} / \mathrm{ml}\end{array}$ \\
\hline \multicolumn{5}{|c|}{ Pelarut Polar Aprotic } \\
\hline 1,4-Dioksana & $\begin{array}{l}\text { I-CH2-CH } \\
\text { 2-O-CH2- } \\
\mathrm{CH} 2-\mathrm{O}-\mathrm{I}\end{array}$ & $\begin{array}{l}101 \\
{ }^{\circ} \mathrm{C}\end{array}$ & 2.3 & $\begin{array}{l}1.033 \\
\mathrm{~g} / \mathrm{ml}\end{array}$ \\
\hline $\begin{array}{l}\text { Tetrahidrofuran } \\
\text { (THF) }\end{array}$ & $\begin{array}{l}\text { I-CH2-CH } \\
\text { 2-O-CH2- } \\
\mathrm{CH} 2-\mathrm{I}\end{array}$ & $\begin{array}{l}66 \\
{ }^{\circ} \mathrm{C}\end{array}$ & 7.5 & $\begin{array}{l}0.886 \\
\mathrm{~g} / \mathrm{ml}\end{array}$ \\
\hline $\begin{array}{l}\text { Diklorometan } \\
\mathrm{a}(\mathrm{DCM})\end{array}$ & $\mathrm{CH}_{2} \mathrm{Cl}_{2}$ & $\begin{array}{l}40 \\
{ }^{\circ} \mathrm{C}\end{array}$ & 9.1 & $\begin{array}{l}1.32 \\
6 \\
\mathrm{~g} / \mathrm{ml}\end{array}$ \\
\hline Acetona & $\begin{array}{l}\mathrm{CH}_{3}-\mathrm{C}= \\
\text { O)- } \mathrm{CH}_{3}\end{array}$ & $\begin{array}{l}56 \\
{ }^{\circ} \mathrm{C}\end{array}$ & 21 & $\begin{array}{l}0.78 \\
6 \\
\mathrm{~g} / \mathrm{ml}\end{array}$ \\
\hline \multicolumn{5}{|c|}{ Pelarut Polar Protic } \\
\hline Asam asetat & $\begin{array}{l}\mathrm{CH}_{3}-\mathrm{C}(= \\
\mathrm{O}) \mathrm{OH}\end{array}$ & $\begin{array}{l}118 \\
{ }^{\circ} \mathrm{C}\end{array}$ & 6.2 & $\begin{array}{l}1.04 \\
9 \\
\mathrm{~g} / \mathrm{ml}\end{array}$ \\
\hline$n$-Butanol & $\begin{array}{l}\mathrm{CH}_{3}-\mathrm{CH}_{2}- \\
\mathrm{CH}_{2}-\mathrm{CH}_{2}- \\
\mathrm{OH}\end{array}$ & $\begin{array}{l}118 \\
{ }^{\circ} \mathrm{C}\end{array}$ & 18 & $\begin{array}{l}0.81 \\
0 \\
\mathrm{~g} / \mathrm{ml}\end{array}$ \\
\hline$n$-Propanol & $\begin{array}{l}\mathrm{CH}_{3}-\mathrm{CH}_{2}- \\
\mathrm{CH}_{2}-\mathrm{OH}\end{array}$ & $\begin{array}{l}97 \\
{ }^{\circ} \mathrm{C}\end{array}$ & 20 & $\begin{array}{l}0.80 \\
3 \\
\mathrm{~g} / \mathrm{ml}\end{array}$ \\
\hline
\end{tabular}




\begin{tabular}{|l|l|l|l|l|}
\hline Etanol & $\begin{array}{l}\mathrm{CH}_{3}-\mathrm{CH}_{2}- \\
\mathrm{OH}\end{array}$ & $\begin{array}{l}79 \\
{ }^{\circ} \mathrm{C}\end{array}$ & 30 & $\begin{array}{l}0.78 \\
9 \\
\mathrm{~g} / \mathrm{ml}\end{array}$ \\
\hline Metanol & $\mathrm{CH}_{3}-\mathrm{OH}$ & $\begin{array}{l}65 \\
{ }^{\circ} \mathrm{C}\end{array}$ & 33 & $\begin{array}{l}0.79 \\
1 \\
\end{array}$ \\
& & & & $\mathrm{~g} / \mathrm{ml}$ \\
\hline
\end{tabular}

Pada proses pengambilan minyak dari biji-bijian, metode yang sering digunakan yaitu ekstraksi pelarut menggunakan pelarut $\mathrm{N}-\mathrm{Heksana}$. $\mathrm{N}$-Heksana umum dijadikan pelarut dikarenakan recovery-nya mudah, bersifat non-polar, dan memiliki selektivitas yang tinggi (Kumar, dll. 2017). Oleh sebab itu, kami menggunakan N-Heksana sebagai pelarut pada proses ekstraksi yang akan kami lakukan. Berikut merupakan sifat-sifat dari N-Heksana.

Tabel 2. Sifat N-HeksanaN-Heksana

\begin{tabular}{|l|c|}
\hline Rumus Molekul & $\mathrm{C}_{6} \mathrm{H}_{14}$ \\
\hline $\begin{array}{l}\text { Warna dan } \\
\text { Wujud }\end{array}$ & Cair, Bening \\
\hline Berat Molekul & $86,18 \mathrm{~g} / \mathrm{mol}$ \\
\hline Berat Jenis & 0,678 \\
\hline Titik Didih & $62-69^{\circ} \mathrm{C}$ \\
\hline
\end{tabular}

(Material Safety Data Sheet)

\section{Spektrofotometri}

Spektrofotometri merupakan salah satu metode dalam kimia analisis yang digunakan untuk menentukan komposisi suatu sampel baik secara kuantitatif dan kualitatif yang didasarkan pada interaksi antara materi dengan cahaya. Peralatan yang digunakan dalam spektrofotometri disebut spektrofotometer. Cahaya yang dimaksud dapat berupa cahaya visibel,
UV dan inframerah, sedangkan materi dapat berupa atom dan molekul namun yang lebih berperan adalah elektron valensi.

$\begin{array}{lll}\text { Spektrofotometri UV-Vis memiliki } & \\ \text { prinsip kerja ketika molekul }\end{array}$ mengabsorbsi radiasi UV atau visible dengan panjang gelombang tertentu, elektron dalam molekul akan mengalami transisi atau pengeksitasian dari tingkat energi yang lebih rendah ke tingkat energi yang lebih tinggi dan sifatnya karakteristik pada tiap senyawa.

Penyerapan cahaya dari sumber radiasi oleh molekul dapat terjadi apabila energi radiasi yang dipancarkan pada atom analit besarnya tepat sama dengan perbedaan tingkat energi transisi elektronnya (Rudi dkk, 2004).

Spektrofotometer UV-VIS dapat diukur dalam bentuk larutan. Analit yang dapat diukur dengan spektrofotometer sinar tampak adalah analit berwarna atau yang dapat dibuat berwarna. Analit berwarna adalah analit yang memiliki sifat menyerap cahaya secara alami. Analit yang dibuat berwarna adalah analit yang tidak berwarna sehingga harus direaksikan dengan zat tertentu untuk membentuk senyawa yang menyerap cahaya pada panjang gelombang tertentu. Pembentukan warna untuk zat atau senyawa yang tidak berwarna dapat dilakukan dengan pembentukan kompleks atau dengan cara oksidasi sehingga analit menjadi berwarna.

\section{Landasan Teori}

Minyak ketumbar adalah minyak atsiri dari biji ketumbar yang berwarna kuning pucat. Minyak ketumbar memiliki titik didih sekitar $193{ }^{\circ} \mathrm{C}$ dengan densitas sebesar $0.868 \mathrm{~g} / \mathrm{mL}$ pada $25{ }^{\circ} \mathrm{C}$ (chemicalbook).

Minyak ketumbar dapat dihasilkan dengan cara ekstraksi padat-cair atau umum disebut leaching. Pada proses ini nantinya akan mengeluarkan zat terlarut dari bahan yang berupa padatan atau akan memurnikan padatan dari cairan yang 
mengkontaminasi padatan. (Kusuma, 2017).

Umumnya pada proses leaching terdapat lima tahap, berpindahnya pelarut dari larutan ke permukaan padatan, menembusnya pelarut ke dalam padatan (difusi intra partikel), larutnya solute dari padatan ke solven, berdifusinya solute melalui campuran ke permukaan padatan (difusi intra partikel), menyebarnya solute pada larutan

(Almohsin, tanpa tahun)

Ekstraksi pelarut merupakan proses yang umum digunakan untuk pengambilan minyak dari biji-bijian. Salah satu pelarut yang umum digunakan adalah pelarut $\mathrm{N}$-Heksana. $\mathrm{N}-\mathrm{H}$ eksana umum digunakan dikarenakan N-heksana mudah di-recovery, non-polar, dan selektivitasnya tinggi (Kumar, dll. 2017). Oleh karena itu, kami menggunakan $\mathrm{N}-$ Heksana sebagai pelarut pada proses ekstraksi yang akan kami lakukan.

\section{METODOLOGI PENELITIAN}

Bahan baku biji ketumbar dan n-heksana, sedangkan alat yang dipergunakan, gelas ukur $250 \mathrm{ml}$, labu ukur $5 \mathrm{ml}$, cawan petri, timbangan, ayakan 30 mesh dan 80 mesh, pipet tetes, botol penyimpanan, piknometer ,stopwatch

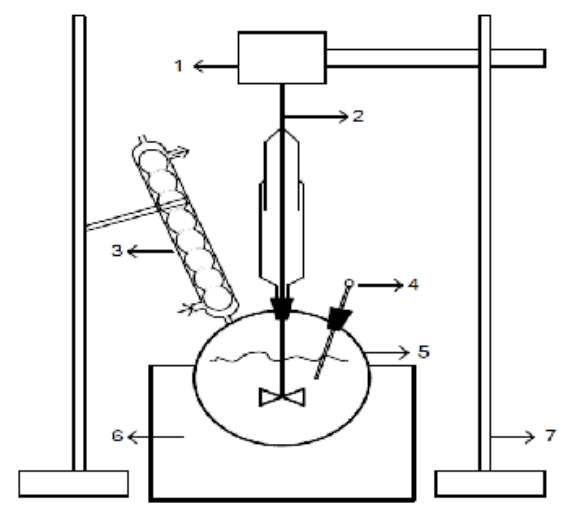

Gambar 1. Rangkaian Alat Ekstraksi

Keterangan :
1. Motor pengaduk

2. Pengaduk mekanik

3. Pendingin balik

4. Thermometer

5. Labu leher tiga

6. Water Bath

7. Statif

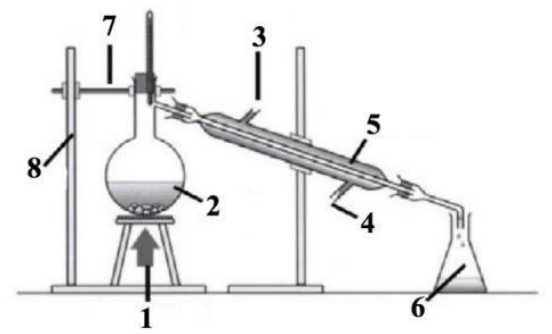

Gambar 2.. Rangkaian Alat Distilasi

Keterangan :

1. Pemanas

2. Labu destilasi

3. Keluaran air pendingin

4. Masukan air pendingin

5. Kondensor

6. Erlenmeyer

7. Klem

8. Statif

\section{Cara Kerja}

\section{Tahap Persiapan}

\section{Persiapan Bahan Baku}

Ketumbar yang didapat dicuci terlebih dahulu untuk membuang kotoran yang terdapat pada permukaan kulit ketumbar. Lalu dikeringkan menggunakan oven sampai berat konstan, dengan suhu $60^{\circ} \mathrm{C}$ Kemudian ketumbar dihaluskan menggunakan blender dan diayak dengan ukuran $-30+80$ mesh.

\section{Tahap Pembuatan Kurva Standar}

\section{a. Penentuan Panjang Gelombang pada Serapan Maksimum}

Menyiapkan minyak ketumbar murni dan larutan blanko (aquadest) dan memasukkannya ke dalam kuvet. 
Selanjutnya, memasukkan kuvet berisi larutan blanko ke dalam spektronik kemudian menekan measure blank yang sebelumnya sudah diatur panjang gelombang $340 \mathrm{~nm}$ dan spektronik sudah dipanasi. Kemudian mengganti kuvet berisi larutan blanko dan kuvet berisi minyak ketumbar murni dan catat absorbansi dan transmitansinya. Setelah itu percobaan dapat diulangi dengan menambahkan intensitas panjang gelombang sebanyak $2 \mathrm{~nm}$ hingga nilai absorbansi mengalami penurunan.

\section{b. Pengukuran Absorbansi pada Berbagai Konsentrasi}

Membuat minyak ketumbar murni dengan berbagai konsentrasi. Selanjutnya, masukkan minyak ketumbar murni ke dalam kuvet sampai indikator batas. Kemudian, masukkan kuvet berisi larutan blanko ke dalam spektronik kemudian menekan measure blank yang sebelumnya sudah diatur panjang gelombang maksimum yang sudah didapat sebelumnya dan spektronik sudah dipanasi. Kemudian mengganti kuvet berisi larutan blanko dan kuvet berisi minyak ketumbar murni, catat absorbansinya. Setelah itu percobaan diulangi dengan konsentrasi minyak ketumbar murni yang berbeda beda.

\section{Tahap Percobaan \\ a. Ekstraksi Ketumbar}

\section{Ekstraksi dengan Variasi Suhu}

Alat dirangkai seperti gambar 1 . Selanjutnya n-heksana dengan volume tertentu dan ketumbar dengan berat tertentu dimasukkan ke dalam labu leher tiga. Nyalakan waterbath hingga suhu pelarut sudah mencapai suhu yang diinginkan, kemudian nyalakan pengaduk dan pencatatan waktu dimulai. Dengan waktu yang telah ditentukan, lakukan uji coba absorbansi dari hasil campuran. Ulangi ekstraksi dengan variasi suhu $45^{\circ} \mathrm{C}, 50^{\circ} \mathrm{C}, 55^{\circ} \mathrm{C}$, 60 , dan $63^{\circ} \mathrm{C}$.

\section{Ekstraksi dengan Variasi Waktu}

Mengulangi percobaan pada poin sebelumnya dengan suhu tetap dengan variasi waktu ekstraksi 90, 120, 150 , 180, 210, dan 240 menit. Suhu ekstraksi dan volume pelarut dibuat konstan.

\section{Ekstraksi dengan Variasi Volume}

Mengulangi percobaan pada poin sebelumnya dengan suhu dan waktu tetap dengan variasi volume pelarut 150 $\mathrm{ml}, 200 \mathrm{ml}, 250 \mathrm{ml}$, dan $300 \mathrm{ml}$. Suhu dan waktu ekstraksi dibuat konstan

\section{Distilasi Minyak Ketumbar}

Hasil ekstraksi kemudian disaring untuk memisahkan padatan ketumbar. Selanjutnya, larutan didestilasi untuk memisahkan minyak ketumbar dari pelarutnya berdasarkan titik didih. Setelah itu dilakukan penimbangan sampai diperoleh berat konstan.

\section{Tahap Pengujian}

Untuk menganalisis hasil minyak ketumbar dilakukan uji densitas dan uji viskositas.

\section{a. Uji Densitas}

Uji densitas dilakukan dengan menggunakan piknometer $25 \mathrm{ml}$ pada suhu kamar. Pertama-tama, timbang piknometer kosong. Kemudian, piknometer diisi dengan minyak ketumbar hingga penuh dan tidak ada gelembung udara, piknometer berisi minyak kemudian ditimbang. Dari hasil penimbangan tersebut, hitung berat minyak dengan mengurangi hasil penimbangan dengan berat piknometer kosong. Setelah mendapat berat minyak, bagi berat dengan volume minyak untuk mendapat densitas dari minyak ketumbar.

\section{b. Uji Viskositas}

Untuk mencari viskositas dari minyak, kami menggunakan alat viskometer redwood. Alat ini dapat membantu menghitung viskositas bahan dari fungsi waktu alir. Untuk menggunakan alat ini, pertama-tama tuang minyak ke dalam tempat bahan (yang akan diuji) hingga batas. 


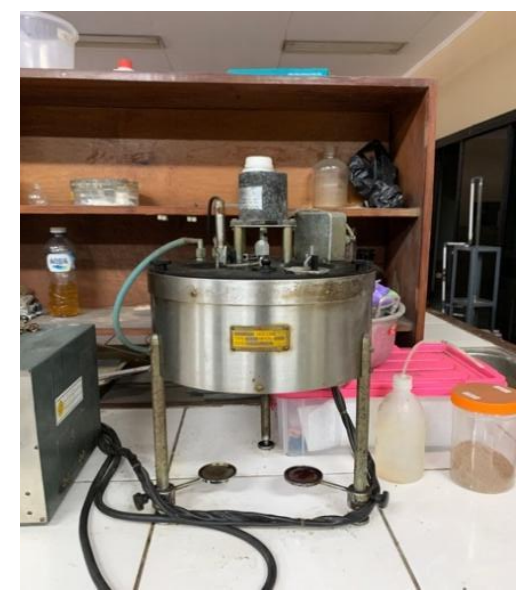

Gambar 3. Viskometer Redwood

Pada bagian keluaran minyak, taruh labu ukur $25 \mathrm{ml}$. Setelah minyak dan labu ukur siap, secara bersamaan buka penutup dan mulai perhitungan waktu menggunakan stopwatch. Hentikan perhitungan waktu saat minyak sudah mencapai batas $25 \mathrm{ml}$ pada labu ukur. Lakukan pengulangan sebanyak tiga kali. Hasil rata-rata dari ketiga perhitungan waktu kemudian digunakan untuk menghitung viskositas minyak.

\section{HASIL DAN PEMBAHASAN Pembuatan Kurva Standar}

\section{Hasil Penentuan Panjang Gelombang pada Serapan Maksimum}

Untuk menentukan panjang gelombang pada serapan maksimum dilakukan pengukuran absorbansi dari minyak ketumbar murni dengan berbagai panjang gelombang, dimulai dari $350 \mathrm{~nm}$ dengan interval $2 \mathrm{~nm}$. Hasil pembacaan absorbansi dapat dilihat pada tabel berikut.

Tabel 3. Hasil Pembacaan Absorbansi Minyak Ketumbar Murni pada Berbagai Panjang Gelombang

\begin{tabular}{|c|c|c|}
\hline No. & $\begin{array}{c}\text { Panjang } \\
\text { gelombang }\end{array}$ & $\begin{array}{c}\text { Absorbansi } \\
(\mathrm{A})\end{array}$ \\
\hline 1. & 350 & 4.283 \\
\hline
\end{tabular}

\begin{tabular}{|c|c|c|}
\hline 2. & 352 & 4.432 \\
\hline 3. & 354 & 4.523 \\
\hline 4. & 356 & 4.564 \\
\hline 5. & 358 & 4.600 \\
\hline 6. & 360 & 4.547 \\
\hline 7. & 362 & 4.434 \\
\hline 8. & 364 & 4.378 \\
\hline
\end{tabular}

Dari hasil tersebut dapat dilihat bahwa serapan maksimum dihasilkan pada panjang gelombang $358 \mathrm{~nm}$, terbukti dari nilai absorbansi dengan panjang gelombang $358 \mathrm{~nm}$ memiliki nilai tertinggi.

\section{Pengukuran Absorbansi pada Berbagai Konsentrasi}

Dari penentuan panjang gelombang diketahui bahwa serapan maksimum dihasilkan pada panjang gelombang 358 $\mathrm{nm}$. Dengan menggunakan panjang gelombang yang sama, dilakukan pengukuran absorbansi minyak ketumbar dengan konsentrasi $10 \%, 5 \%$, $3 \%$, dan $1 \%$ dalam pelarut $\mathrm{N}$-heksana. Hasil pembacaan absorbansi dapat dilihat pada tabel 4 berikut.

Tabel 4. Hasil Pembacaan Absorbansi pada Berbagai Konsentrasi Minyak Ketumbar

\begin{tabular}{|c|c|c|}
\hline No. & Konsentrasi & Absorbansi (A) \\
\hline 1. & $10 \%$ & 3,117 \\
\hline 2. & $5 \%$ & 2,686 \\
\hline 3. & $3 \%$ & 0,982 \\
\hline 4. & $1 \%$ & 0,273 \\
\hline
\end{tabular}




\section{Pengaruh Suhu Terhadap Hasil Ekstraksi Minyak Ketumbar}

Pada ekstraksi minyak ketumbar dengan dengan variasi suhu $45^{\circ} \mathrm{C}$, $50^{\circ} \mathrm{C}, 55^{\circ} \mathrm{C}, 60$, dan $63^{\circ} \mathrm{C}$ menunjukkan nilai absorbansi yang berbeda. Dari persamaan matematis hubungan antara konsentrasi minyak dalam N-Heksana dengan absorbansi dapat didapat hasil konsentrasi sebagai berikut:

Tabel 5. Pengaruh Suhu Ekstraksi terhadap Hasil Minyak Ketumbar

\begin{tabular}{|c|c|c|c|c|c|}
\hline No. & $\begin{array}{c}\text { Suhu } \\
\left({ }^{\circ} \mathrm{C}\right)\end{array}$ & $\begin{array}{c}\text { Absor } \\
\text { bansi }\end{array}$ & $\begin{array}{c}\text { Konsentr } \\
\text { asi (\%) }\end{array}$ & $\begin{array}{c}\text { Hasil } \\
\text { Mi } \\
\text { nyak } \\
(\mathrm{ml})\end{array}$ & $\begin{array}{c}\text { Yield } \\
(\%)\end{array}$ \\
\hline 1. & 45 & 0.106 & 0,334 & $\begin{array}{c}0,66 \\
8\end{array}$ & $\begin{array}{c}0,79 \\
9\end{array}$ \\
\hline 2. & 50 & 0.113 & 0,356 & $\begin{array}{c}0,71 \\
2\end{array}$ & $\begin{array}{c}0,85 \\
2\end{array}$ \\
\hline 3. & 55 & 0.147 & 0,463 & $\begin{array}{c}0,92 \\
6\end{array}$ & $\begin{array}{c}1,10 \\
9\end{array}$ \\
\hline 4. & 60 & 0.176 & 0,554 & $\begin{array}{c}1,10 \\
9\end{array}$ & $\begin{array}{c}1,32 \\
7\end{array}$ \\
\hline 5. & 63 & 0.200 & 0,630 & $\begin{array}{c}1,26 \\
0\end{array}$ & $\begin{array}{c}1,50 \\
8\end{array}$ \\
\hline
\end{tabular}

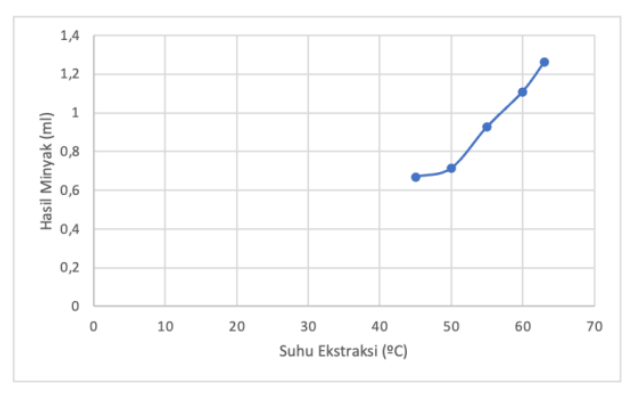

Gambar 4. Kurva Perngaruh Suhu Ekstraksi Terhadap Hasil Minyak Ketumbar
Dari gambar 4. dapat dilihat bahwa hasil minyak terus naik sampai suhu $63^{\circ} \mathrm{C}$. Hal ini membuktikan bahwa kenaikan suhu akan meningkatkan jumlah zat terlarut ke dalam pelarut. Tetapi hal ini harus memperhatikan titik didih pelarutnya yaitu $n-H e k s a n a$. Suhu pada proses ekstraksi terbatas hingga suhu titik didih pelarut (Anonim, 2015). Sesuai teori, titik didih dari pelarut $\mathrm{N}-H e k s a n a$ ialah $62-69^{\circ} \mathrm{C}$. Maka dari itu kami mengambil $63^{\circ} \mathrm{C}$ sebagai batas maksimum.

\section{Pengaruh Waktu Ekstraksi terhadap Hasil Ekstraksi Minyak Ketumbar}

Salah satu faktor yang mempengaruhi ekstraksi adalah waktu proses ekstraksi. Pada percobaan kami, kami melakukan variasi waktu ekstraksi yaitu pada $90,120,150,180,210$, dan 240 menit. Hasil minyak dari percobaan dengan variasi waktu ekstraksi dapat dilihat pada tabel berikut.

Tabel 6.. Pengaruh Waktu Ekstraksi terhadap Hasil Minyak Ketumbar

\begin{tabular}{|c|c|c|c|c|c|}
\hline No & $\begin{array}{l}\text { Waktu } \\
\text { menit }\end{array}$ & $\begin{array}{c}\text { Abso } \\
\text { rbans } \\
\text { i }\end{array}$ & $\begin{array}{c}\text { Kon } \\
\text { sentr } \\
\text { asi } \\
(\%)\end{array}$ & $\begin{array}{c}\text { Hasil } \\
\text { Mi } \\
\text { nyak } \\
(\mathrm{ml})\end{array}$ & $\begin{array}{c}\text { Yiel } \\
\text { d } \\
(\%)\end{array}$ \\
\hline 1. & 90 & 0.163 & 0,513 & 1,027 & $\begin{array}{l}1,2 \\
29\end{array}$ \\
\hline 2. & 120 & 0.176 & 0,554 & 1,109 & $\begin{array}{l}1,3 \\
27\end{array}$ \\
\hline 3. & 150 & 0.207 & 0,652 & 1,304 & $\begin{array}{l}1,5 \\
61\end{array}$ \\
\hline 4. & 180 & 0.204 & 0,643 & 1,285 & $\begin{array}{l}1,5 \\
38\end{array}$ \\
\hline 5. & 210 & 0.201 & 0,633 & 1,266 & $\begin{array}{c}1,5 \\
16\end{array}$ \\
\hline 6. & 240 & 0,198 & 0,624 & 1,245 & $\begin{array}{l}1,4 \\
93\end{array}$ \\
\hline
\end{tabular}




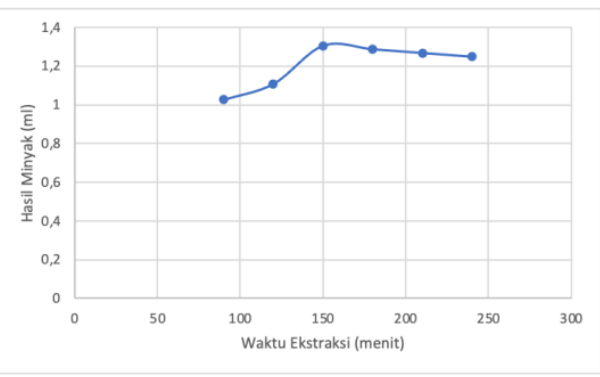

Gambar 5 Kurva Perngaruh Waktu Ekstraksi Terhadap Hasil Minyak

Dilihat pada tabel 6 menunjukkan waktu optimum untuk mengambil minyak atsiri terletak pada 150 menit. Dalam pengambilan minyak atsiri tentunya waktu sangatlah berpengaruh. Hal ini dapat dibuktikan dengan data diatas semakin lama waktu semakin banyak minyak yang didapat sekaligus membuktikan pengambilan minyak dapat dioptimalkan pada waktu 150 menit.

Namun, pada waktu 180 menit, 210 menit, dan 240 menit rendemen minyak yang terambil tidak terlalu berbeda dengan waktu 150 menit, hal tersebut dapat terjadi dikarenakan reaksi ekstraksi sudah mencapai titik jenuhnya sehingga minyak atsiri sudah maksimal pada waktu 150 menit. Maka dapat disimpulkan waktu optimum untuk pengambilan minyak atsiri adalah 150 menit.

\section{Pengaruh Volume Pelarut terhadap Hasil Ekstraksi Minyak Ketumbar}

Pada percobaan ini juga dilakukan ekstraksi dengan variasi volume pelarut. Data hasil minyak pada berbagai volume pelarut dapat dilihat pada tabel berikut.

Tabel 7. Pengaruh Volume Pelarut terhadap Hasil Minyak Ketumbar

\begin{tabular}{|c|c|c|c|c|c|}
\hline $\begin{array}{c}\text { No } \\
\cdot\end{array}$ & $\begin{array}{c}\text { volu } \\
\mathrm{me} \\
(\mathrm{mL})\end{array}$ & $\begin{array}{c}\text { absor } \\
\text { bansi }\end{array}$ & $\begin{array}{c}\text { Kon } \\
\text { sen } \\
\text { trasi } \\
(\%)\end{array}$ & $\begin{array}{c}\text { Hasil } \\
\mathrm{Mi} \\
\mathrm{nyak} \\
(\mathrm{ml})\end{array}$ & $\begin{array}{c}\text { Yield } \\
(\%)\end{array}$ \\
\hline 1. & 100 & 0.393 & 1,238 & 1,238 & 1,482 \\
\hline 2. & 150 & 0.269 & 0,847 & 1,271 & 1,521 \\
\hline 3. & 200 & 0.207 & 0,652 & 1,304 & 1,561 \\
\hline 4. & 250 & 0.152 & 0,479 & 1,197 & 1,433 \\
\hline 5. & 300 & 0.117 & 0,369 & 1,106 & 1,323 \\
\hline
\end{tabular}

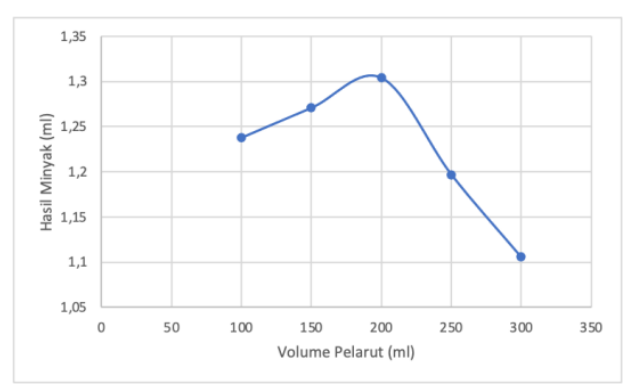

Gambar 6. Kurva Pengaruh Volume Pelarut Terhadap Hasil Minyak

Jumlah volume yang digunakan pada minyak atsiri tentunya sangat berpengaruh terhadap pengambilan minyak atsiri itu sendiri, Hal ini dikarenakan pelarut tersebut memiliki titik optimum untuk mengekstrak suatu bahan dengan perbandingan massa dan pelarut tertentu. Dapat dilihat pada gambar 6 menunjukkan bahwa semakin banyak volume pelarut yang digunakan akan mendapatkan rendemen minyak yang lebih banyak. Hal ini sesuai 
dengan teori bahwa semakin banyak pelarut maka pemecahan dinding dan membran sel akibat perbedaan tekanan antara dalam dan luar sel berjalan lebih optimal sehingga semakin banyak rendemen yang terambil (Koirewoa, 2012). Namun, dapat dilihat pada gambar 5 bahwa terjadi penurunan rendemen minyak yang dihasilkan dengan volume pelarut $250 \mathrm{ml}$ dan 300 $\mathrm{ml}$. Hal ini disebabkan karena jumlah volume yang terlalu besar dapat mengakibatkan turbulensi semakin kecil sehingga berpengaruh pada rendemen yang berkurang (Kusmartono, 2016).

\section{Kesimpulan}

Dari penelitian yang sudah dilakukan, dapat diambil beberapa kesimpulan sebagai berikut :

1. Suhu optimum ekstraksi biji ketumbar dengan pelarut $\mathrm{N}$-Heksana yaitu pada $63^{\circ} \mathrm{C}$ dengan banyak minyak yang dihasilkan sebanyak $1,260 \mathrm{ml}$.

2. Waktu optimum ekstraksi biji ketumbar dengan pelarut $\mathrm{N}-H e k s a n a$ yaitu pada 150 menit dengan banyak minyak yang dihasilkan sebanyak $1,561 \mathrm{ml}$.

3. Volume pelarut optimum ekstraksi biji ketumbar dengan pelarut $\mathrm{N}-\mathrm{Heksana}$ yaitu pada $200 \mathrm{ml}$ dengan banyak minyak yang dihasilkan sebanyak $1,561 \mathrm{ml}$.

\section{DAFTAR PUSTAKA}

Anonim. 2015. Faktor-Faktor yang Mempengaruhi Ekstraksi. https://dokumen.tips/download/lin k/faktor-faktor-yang-mempengaru hi-ekstraksi [21 November 2019]

Ariyani, Fransiska, dkk. 2008. Ekstraksi Minyak Atsiri dari Tanaman Sereh dengan Menggunakan Pelarut Metanol, Aseton, dan N-Heksana. WIDYA TEKNIK Vol. 7, No.2, (124-133).
Astawan, M. 2009. Ketumbar. http://cybehealt.cbn.net.id [24 December 2019]

ETH Zurich. 2014. Practica in Process Engineering II. Zurich: IPE Separation Process laboratory

Fauci, B., K. Hauser, Longo, \& Jameson. 2008. Princiciples of Internal Medicine. 17th Ed. McGraw Hill Companies, New York.

Fishersci. Material Data Safety Sheet (MSDS).

https://fscimage.fishersci.com/ms ds/10951.htm. [9 Maret 2021]

Gamse, Thomas. Extraction, Liquid Liquid Extraction, Solid - Liquid Extraction, High Pressure Extraction. Graz : Department of Chemical Engineering and Environmental Technology Graz University of Technology

Indradjaja, Suryadi. 2017. Leaching (Ekstraksi Padat Cair). https://docplayer.info/43823621-L eaching-ekstraksi-padat-cair.html [21 November 2019]

Koirewoa, Y.A., dkk. 2012. Isolasi dan Identifikasi Senyawa Flavonoid dalam Daun Beluntas. Manado: FMIPA UNSRAT

Kumar, dll. 2017. Green solvents and technologies for oil extraction from oilseeds. Chemistry Central Journal. 11:9

Kusmartono, Bambang \& Aning Yulianingtyas. 2016. Optimasi Volume Pelarut dan Waktu Maserasi Pengambilan Flavonoid Daun Belimbing Wuluh (Averrhoa Bilimbi L). Yogyakarta: Jurusan Teknik Kimia IST AKPRIND

Kusuma, Kurnia Arifiani. 2017. Leaching (Ekstraksi Padat-Cair). https://kupdf.net/download/leachin g-ekstraksi-padat-cair-repaired 5 a070f4ce2b6f51148c0e653_pdf [21 November 2019]

Rahayu, Siti. 2017. Isolasi Pektin dari Kulit Pepaya (Carica Papaya L.) dengan Metode Refluks Menggunakan Pelarut $\mathrm{HCl}$ Encer. 
Palembang: Politeknik Negeri Sriwijaya.

Rashid, M.M, dkk. 2014. Effect of different levels of Dhania seed (Coriandrum sativum) on the performance of broilers. Bangladesh: Bangladesh Journal of Animal Science.

Mandal, Manisha dan Shyamapada Mandal. 2015. Coriander (Coriandrum sativum L.) essential oil: Chemistry and biological activity. India: Asian Pacific Journal of Tropical Biomedicine.

McCabe, W., Smith, J.C., and Harriot, P..1993. Unit Operation of Chemical Engineering. United States of America: McGraw Hill Book, Co.,

NHR Organic Oils. Material Data Safety Sheet (MSDS). https://www.nhrorganicoils.com/u ploads/20151110145600e Corian der Seed SDS.pdf. [9 Maret 2021]

Pubchem.

Hexane.

https://pubchem.ncbi.nlm.nih.gov/ compound/Hexane

Purseglove. J.W., E.G. Brown, C.L. Green and S.R.J. Robbins. 1981. Spice. Vol II. Longman. London.

Sakinah, Asri Nisa. 2016. Kajian Produksi Sirup Gula dari Daun Stevia (Stevia Rebaudiana Bertoni ) Terhadap Karakteristik Sirup Gula. Bandung: Universitas Pasundan.

Sumaatmadja, D. 1981. Prospek Pengembangan Industri Oleoresin di Indonesia Komunikasi 201. Bogor: Balai besar Industri Hasil Pertanian.

\section{BIODATA PENULIS}

Ir. Abdullah Kunta Arsa, M.T. lahir di Yogyakarta tanggal 16 Februari 1957, menyelesaikan pendidikan S1 bidang ilmu Teknik Kimia dari UPN "Veteran" Yogyakarta tahun 1988, dan S2 bidang ilmu Teknik Kimia dari Universitas Gadjah Mada tahun 2000. Saat ini tercatat sebagai
Dosen Tetap Jurusan Teknik Kimia, Universitas Pembangunan Nasional "Veteran" Yogyakarta dengan jabatan akademik Lektor pada bidang minat teknik kimia.

Ir. Zubaidi Achmad, M.T., lahir di Bantul tanggal 3 Oktober 1959, menyelesaikan pendidikan S1 bidang Teknik Kimia di UPN "Veteran" Yogyakarta tahun 1987 dan S2 bidang Teknik Kimia di Universitas Gadjah Mada Yogyakarta tahun 1998. Saat ini tercatat sebagai Dosen Tetap Jurusan Teknik Kimia, UPN "Veteran" Yogyakarta dengan jabatan akademik Lektor Kepala pada bidang minat teknologi proses.

Ir. Purwo Subagiyo, MT lahir :Yogyakarta 10 Desember 1956,

Bidang IImu S1 Teknik Kimia di UPN "Veteran" Yogyakarta tahun 1991 dan S2 bidang Teknik Kimia di Universitas Gadjah Mada Yogyakarta tahun 2002. Saat ini tercatat sebagai Dosen Tetap Jurusan Teknik Kimia, UPN "Veteran" Yogyakarta dengan jabatan akademik Asisten AHli pada bidang minat teknologi proses. 